\title{
Genesis and Tactics of Bullwhip in Supply Chain Effect Using SD Simulation
}

\author{
Shupei Liu, Qiang Sun* \\ Business School, Shandong University of Technology, Zibo, China.
}

How to cite this paper: Shupei Liu, Qiang Sun. (2021) Genesis and Tactics of Bullwhip in Supply Chain Effect Using SD Simulation. Journal of Applied Mathematics and Computation, 5(2), 73-83.

DOI: $10.26855 /$ jamc.2021.06.002

Received: March 19, 2021

Accepted: April 17, 2021

Published: April 30, 2021

*Corresponding author: Qiang Sun, Business School, Shandong University of Technology, Zibo, China.

Email: sunqiang@sdut.edu.cn

\begin{abstract}
Bullwhip effect not only distorts demand information but also reduces the ability to response fluctuations in market demand of entire supply chain. Advancing research on evolution mechanism of bullwhip effect and analyzing control strategies will have important practical significance for stable supply chain development. This paper constructs a model of three-level supply chain that includes retailers, wholesalers and suppliers as the main entities and reports the results of simulating models with different structures and vendor managed inventory. The results shows that bullwhip effect does exist in supply chains and that the effects of fluctuations in three parameters of inventory level, sales prediction and ordering rate gradually increase in magnitude along supply chain to different degrees. Both supply chain level and inventory management method have a direct impact on bullwhip effect. On this basis, practical measures such as information sharing and supply chain structure optimization can be used to alleviate bullwhip effect.
\end{abstract}

\section{Keywords}

Bullwhip Effect, System Dynamics, Supply Chain, Vendor Managed Inventory

\section{Introduction}

A supply chain system is a functional network composed of raw material suppliers, manufacturers, distributors, retailers, and end users. It integrates three basic streams of logistics flow, information flow, capital flow and is an important part of any economic system [1]. Not only is it a material chain linking initial raw material processing and production to final product consumption, but more importantly, it can realize the addition of value in resource allocation and in product manufacturing, distribution and consumption through reasonable supply chain operation and management [2]. Therefore, supply chain system is the most important value-adding chain in an economic system. However, due to its own inherent characteristics and uncertainty of external environment, supply chain system exhibits a high degree of complexity and is highly dynamic [3]. On the one hand, the diversity and variability of consumer demand causes the production activities in supply chain to vary dynamically with changes in market demand [4]. On the other hand, the intensification of market competition and disruption of economic environment can lead to complex conflicts of interest among various companies participating in supply chain. Production operations between nodes are subject to restrictions and mutual interactions as products pass through supply chain system [5]. Due to asynchronous and uncertain nature of information transfer, demand information is often not effectively communicated between the members of supply chain due to various factors affecting the process of delivering downstream information from end customers up supply chain to raw material suppliers [6]. The demand information may be amplified in each step of chain or even severely distorted. Eventually, demand issued from one level to the next higher level will be much greater than the actual number of orders required at the current level. This is the bullwhip effect.

Since the concept of bullwhip effect was proposed, scholars have achieved great advancements in their research [7]. 
Many scholars have found that errors in demand forecasting are an important cause of bullwhip effect because inaccurate predictions will affect order planning and inventory control for enterprises in supply chain [8]. Vendors arrange output, purchase plans and predictions based on historical customer demand data, orders from downstream companies will be processed by upstream companies as forecast information, resulting in upstream distortion of downstream company order information [9]. These upstream enterprises suffer from greater errors in demand forecasting and will further increase the quantities of raw materials ordered from upstream suppliers, which leading to an increase in demand for entire supply chain [10]. In addition, asymmetry of information is another important cause of bullwhip effect.

Bullwhip effect leads to the distortion of demand information, making it impossible for upstream companies in supply chain to accurately grasp market demand and disturbing normal production plans of enterprises, reducing their response ability to demand fluctuations, causing inventory backlogs or shortages. This causes entire supply chain to become misaligned, increased operating costs for companies and lower customer service levels among supply chain entities. Since it was first described, bullwhip effect has become a focus of attention in practice and theory of supply chain management. In the face of ever-changing economic environment and increasingly fierce market competition, it will be necessary to conduct further research on the conditions, influencing factors and evolution mechanisms related to bullwhip effect to strengthen the study and application of coping strategies and methods for controlling bullwhip effect. Understanding the impact of bullwhip effect on companies has important practical significance for improving the efficiency of supply chains, enhancing the competitiveness of enterprises, preventing external shocks, achieving healthy and stable economic development.

\section{Literature review}

In recent years, the academic community has paid increasing attention to bullwhip effect. Bullwhip effect refers to inevitable amplification of demand in supply chain management. Bullwhip effect leads to the distortion of demand information, an increase in inventory investment costs, inefficient production planning and a low level of service, ultimately leading to supply chain imbalance and a decline in corporate profits.

Various studies on bullwhip effect have been reported in literature. At present, some scholars have applied methods of robust cybernetics, anti-bullwhip effect, prediction methods and recursive algorithms to weaken bullwhip effect [11-14]. Some scholars have also systematically studied the causes of bullwhip effect. With the whole supply chain as study object, investigations of bullwhip effect in supply chain cannot accurately reveal the influence of relationships between enterprises forming nodes of supply chain. It is easy to overlook certain characteristics of these node enterprises themselves that are important factors, in combination with the complexity of influence of relationships between enterprises, these difficulties can result in the establishment of a simulation model solely on the basis of factors that characterize the system as a whole. However, such a model cannot accurately reflect the different influences of each enterprise, and consequently the established simulation model contains certain discrepancies between modelled supply chain nodes and actual operations of enterprises.

System dynamics is a discipline that focuses on analysis of information feedback systems, and it is also a cross-disciplinary area involving the recognition and solution of problems in such systems [15]. The earliest application of system dynamics to supply chains was bullwhip effect. Through system dynamics simulations, researchers found that bullwhip effect exists in supply chains and that this phenomenon is deserving of close attention [16]. Subsequently, dynamic simulation analyses for diagnosis, optimization and decision-making with regard to bullwhip effect were performed. Various factors influencing demand amplification that is characteristic of bullwhip effect, such as complexity and time pressure of inventory management, delay of demand information, and issues related to productivity and manpower were examined. In addition, studies on factors influencing bullwhip effect have focused on just-in-time production model, customer service levels, total costs, and responses of customers and markets [17].

The earliest systematic study of bullwhip effect from a quantitative perspective addressed rational decision-making behaviour of managers seeking to maximize their own profits. This study identified four main causes of bullwhip effect: demand prediction, rationing of supply, fluctuations in order quantity and price. Scholars have since carried out more detailed research on each of these four main causes. The existing literature on bullwhip effect has mainly focused on supply chain structure and information sharing. The causes of bullwhip effect can be classified into two categories: business operations and behaviour of supply chain participants [18]. The causes of business operations mainly include order delivery times, inventory policy and replenishment strategies, supply chain structure, consistency of corporate activities and business processes. Behaviour of supply chain participants mainly include time delays in the order decision-making process, information sharing behaviours, and attitudes towards risk.

In this paper, methods of system dynamics are used to simulate bullwhip effect consisting of manufacturers, wholesalers and retailers as nodes of network. Three parameters, inventory levels, sales forecasts and delivery rates are considered to study the existence of bullwhip effect. Analysis of bullwhip effect in supply chain system can reveal the main 
causes of bullwhip effect, thus enabling a breakthrough in suppressing bullwhip effect to minimize demand fluctuations in supply chain and improve the response to market demand. The development of feasible control strategies for bullwhip effect will facilitate integration of theoretical research into management practice, thereby promoting the optimal allocation of system resources in supply chain operations and enabling overall optimization of supply chain system.

\section{Materials and Methodology}

\subsection{System structure modeling and problem identification}

System structure modelling is an important prerequisite for system dynamics research. System modelling is mainly used to analyse and design systems, predict system development trends and implement optimal system control. The most important flows in supply chain management are the logistics flow, information flow and capital flow. This paper considers a three-level model of supply chain system. A three-level supply chain model generally includes three types of supply chain nodes: suppliers, wholesalers and retailers. Retailers interact directly with customers, who have the most accurate grasp of changes in market demand and are also the source of market demand. When the demand for a commodity increases, a retailer issues order information to a wholesaler. If the wholesaler has sufficient inventory, the wholesaler can immediately supply the retailer to meet the market demand. Otherwise, if the wholesaler has a shortage of stock, the wholesaler sends order information to a supplier. The system structure is shown in Figure 1.

This paper mainly studies bullwhip effect in three-level supply chain on the basis of order and inventory information of each supply chain node. Due to the backlog caused by bullwhip effect, inventory fluctuations are relatively large, meaning that inventory is not sufficiently stable, resulting in high costs and a loss of competitive advantage. Therefore, measures are urgently needed to weaken bullwhip effect, thereby reducing costs incurred and enabling the establishment of a stable competitive advantage. To this end, through the modelling and simulation of supply chain, our aim is to find the cause of bullwhip effect and then identify a better supply chain structure to weaken the influence of bullwhip effect.

\subsection{Construction of the causal loop diagram}

There are two delays in three-level supply chain. One is the delay in information exchange process, which is the feedback process from retailers to wholesalers. The other is delay in material supply process, which represents the time required by wholesalers to meet the retailer's order requirements. When satisfying the demand from retailer, wholesaler's inventory will be reduced. In turns, an increase in order quantity from wholesaler will cause supplier to increase the quantity ordered from the next upstream supplier. In this process, a similar delay will be incurred before market demand can be responded to. Thus, the overall causal circuit diagram is a negative feedback system consisting of retailer's inventory, retailer ordering, wholesaler's inventory, wholesaler ordering, and supplier's inventory. The causal relationships are shown in Figure 2.

Figure 2 includes a positive feedback loop and a negative feedback loop. The positive feedback loop is as follows: inventory level of retailers---order quantity of retailers---shipment quantity of wholesalers-inventory level of wholesalers---purchasing quantity of wholesalers---outbound quantity of producers---inventory level of producers---production quantity of producers---inventory level of retailers. That is, as retailers' inventories decrease, retailers' order volume increases accordingly, resulting in an increase in wholesale shipments. As wholesalers' inventories decrease, purchasing quantity of wholesalers will increase, which will increase output of manufacturers. As inventories decrease, larger production orders will be placed with manufacturers, resulting in an increase in orders upstream of retailers, ultimately resulting in an increase in retailer inventories.

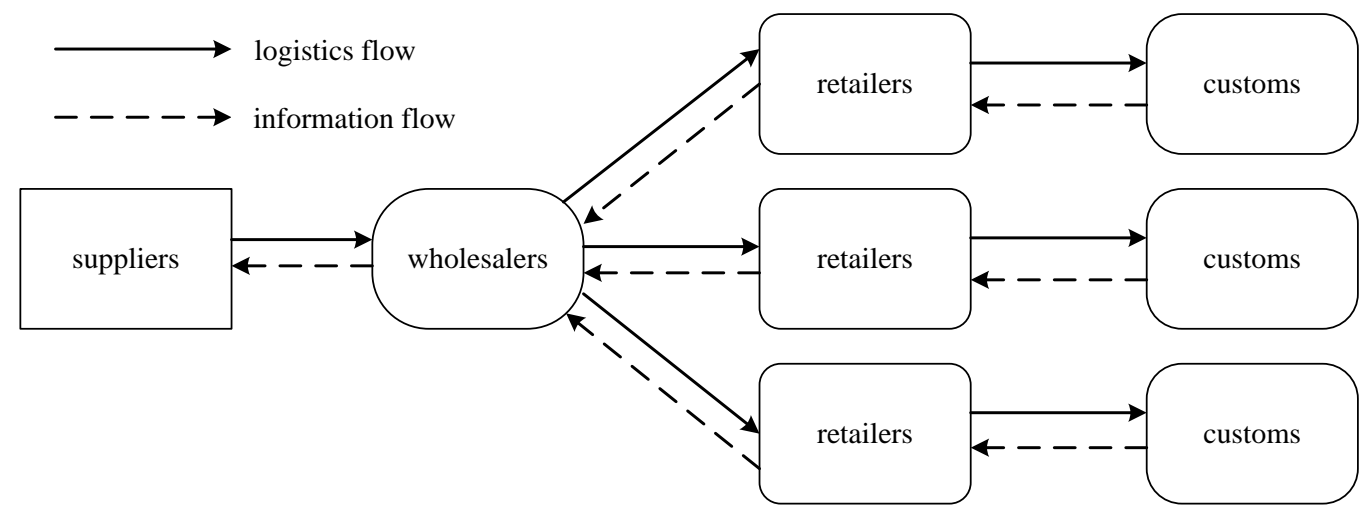

Figure 1. Structure of supply chain system. 


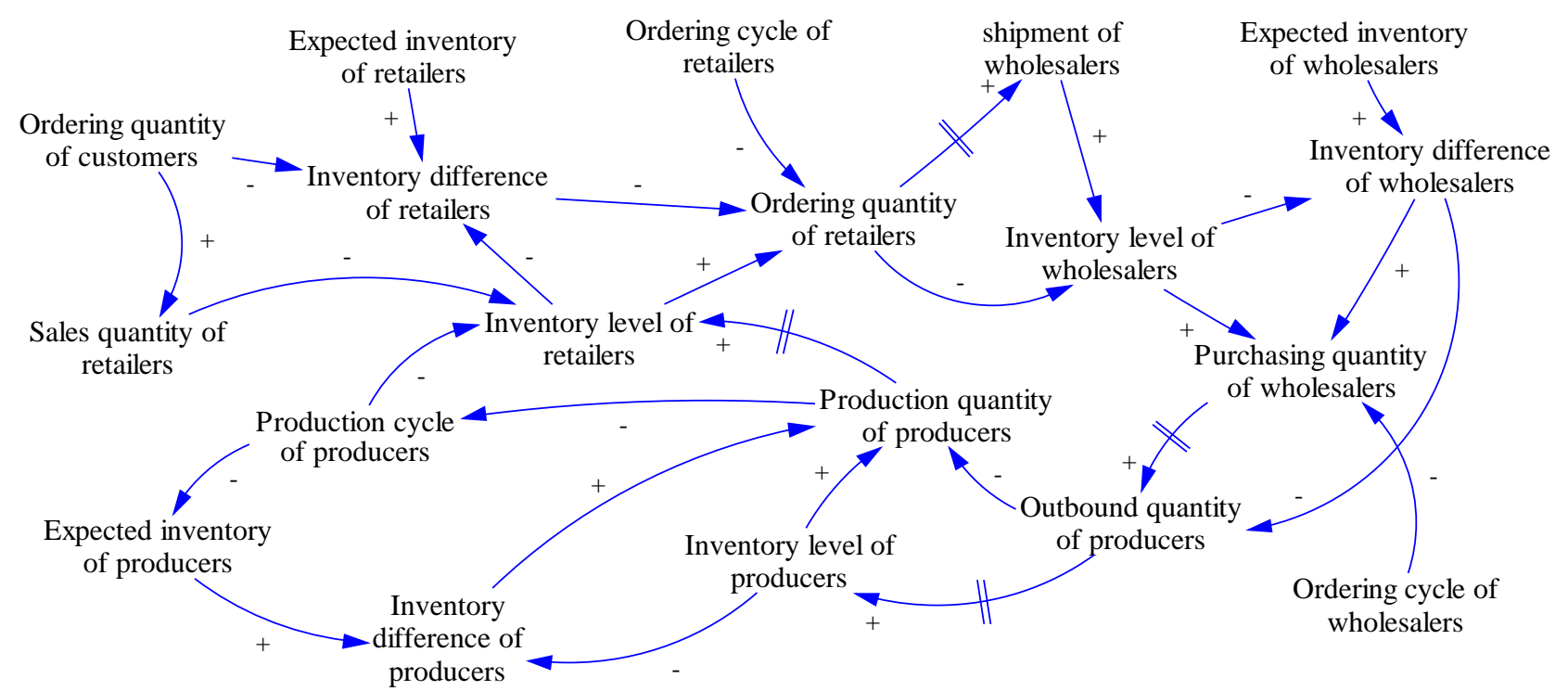

Figure 2. Causal loop diagram for the three-level supply chain.

The negative feedback loop is as follows: inventory difference of retailers---order quantity of retailers---inventory level of wholesalers---inventory difference of wholesalers---outbound quantity of producers---production quantity of producers---production cycle of producers---inventory level of retailers---inventory difference of retailers. That is, as retailers' inventories decrease, inventories of wholesalers will also decrease, leading to a decrease in inventories of manufacturers. The reduction in wholesale inventories will cause manufacturers to increase their inventories because retailers' order quantity is certain, and this will reduce inventory difference of retailers to a certain degree.

\subsection{Construction of the system flow chart}

The first step in drawing system flow chart based on a causal relationship diagram is to identify horizontal and rate variables. According to the relationship analysis in Figure 2, three variables, namely, inventory of retailers, inventory of wholesalers and inventory of producers are selected as horizontal variables. The market demand rate, delivery rate of wholesalers, delivery rate of producers and production rate of producers are selected as system rate variables in supply chain system. The system flow chart is shown in Figure 3.

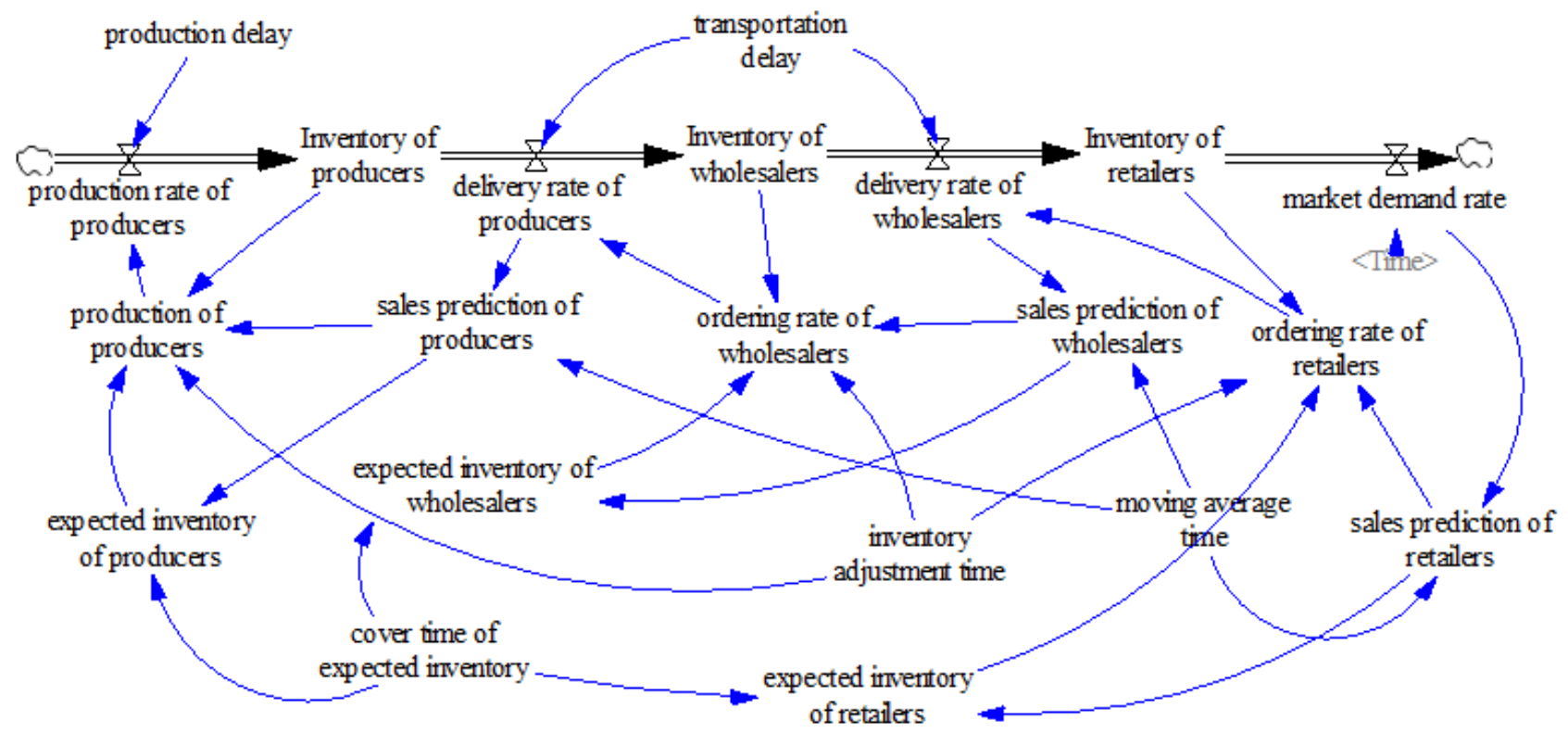

Figure 3. System flow chart for the three-level supply chain. 


\subsection{Establishment of the simulation equations}

Through the analysis of system flow chart and causal relationships between variables in three-level supply chain system, the logical relationships between variables can be clearly identified. The quantitative relationships between system variables need to be analysed. There are 22 variables in the model, including 3 horizontal variables, 4 rate variables, 10 auxiliary variables and 5 constants. The initial assignments of variable expressions and constant values are presented as follows.

Inventory of retailers=INTEG (delivery rate of wholesalers-market demand rate, 1000)

Inventory of wholesalers=INTEG (delivery rate of producers-delivery rate of wholesalers, 1000)

Inventory of producers=INTEG (production rate of producers-delivery rate of producers, 1000)

Market demand rate=300+IF THEN ELSE (TIME>4, RANDOM EXPONENTIAL $(-200,200,0,100,4), 0)$

Production rate of producers=DELAY3 (production of producers, production delay)

Delivery rate of producers=DELAY3 (ordering rate of wholesalers, transportation delay)

Delivery rate of wholesalers=DELAY3 (ordering rate of retailers, transportation delay)

Ordering rate of retailers=MAX (0, sales prediction of retailers+(expected inventory of retailers-inventory of retailers)/inventory adjustment time)

Expected inventory of retailers=coverage time of expected inventory*sales prediction of retailers

Sales prediction of retailers=SMOOTH (market demand rate, moving average time)

Delivery rate of wholesalers=DELAY3 (ordering rate of retailers, transportation delay)

Expected inventory of wholesalers=coverage time of expected inventory*sales prediction of wholesalers

Ordering rate of wholesalers=MAX ( 0 , sales prediction of wholesalers+ (expected inventory of wholesalers-inventory of wholesalers)/inventory adjustment time)

Sales prediction of wholesalers=SMOOTH (delivery rate of wholesalers, moving average time)

Expected inventory of producers=coverage time of expected inventory*sales prediction of producers

Production of producers=MAX (0, sales prediction of producers+(expected inventory of producers-inventory of producers)/inventory adjustment time)

Sales prediction of producers=SMOOTH (delivery rate of producers, moving average time)

Inventories and expected inventories of retailers, wholesalers and producers are all expressed in units of pieces. Delivery rates, sales predictions and ordering rates of retailers, wholesalers and producers are expressed in units of pieces/week. Delivery rates of wholesalers and retailers are expressed in units of pieces/week. Production rate of producers, production of producers and market demand rate are expressed in units of pieces/week.

In addition, the parameters of simulation are set as follows: INITIAL TIME=0 weeks, FINAL TIME=100 weeks, and SAVEPER=TIME STEP=1 week, corresponding to 100 weeks of simulation cycles. The values of constant parameters are presented as follows: production delay of producers $=3$, inventory adjustment time $=4$, coverage time of expected inventory $=3$, moving average time $=5$ and transport delay $=3$.

\section{Results}

This paper collects relevant data from field research on supply chains reflecting the inventories, sales forecasts and delivery rates of retailers, wholesalers and producers. Based on the assumptions of these previous data and of simulation model constructed above, inventory dynamics, sales forecasts and delivery rates were simulated with Vensim 5.6 software. The results are shown in Figure 4.

\subsection{Inventory levels under bullwhip effect}

Figure 4A and Figure 4B show expected inventory and inventory levels of producers, retailers and wholesalers. The overall trend of inventory variations in three-level supply chain is similar to that of expected inventory variations. Inventory of the terminal retailers exhibits small fluctuations with time, mainly due to the continuous impact of daily retail on their individual inventories. Inventory fluctuations of wholesalers are larger than those of retailers, while inventory fluctuations of upstream suppliers are the most pronounced. After 3 weeks, inventories of wholesalers and producers have started to fluctuate following inventory fluctuations of retailers. The maximum inventory of retailers is observed at 37 weeks, and the maximum inventory of wholesalers appears at the end of 45 weeks, lagging behind the maximum inventory of retailers. This is because of the delays of information and logistics, which cause wholesalers to be unable to satisfy the ordering rate of retailers in a timely manner, resulting in valley and peak lag. The fluctuation cycle for wholesalers is longer than that for the retailers. This is because purchase frequency of wholesalers is lower, but the quantity purchased is larger. Inventory fluctuation amplitudes in supply chain serve as good proof of bullwhip effect.

Expected inventories of retailers, wholesalers and producers show similar fluctuations under the influence of bullwhip 
effect. That is, small fluctuations in expected inventory of retailers cause large fluctuations in expected inventory of wholesalers and suppliers, leading to even larger fluctuations in expected inventory of producers.

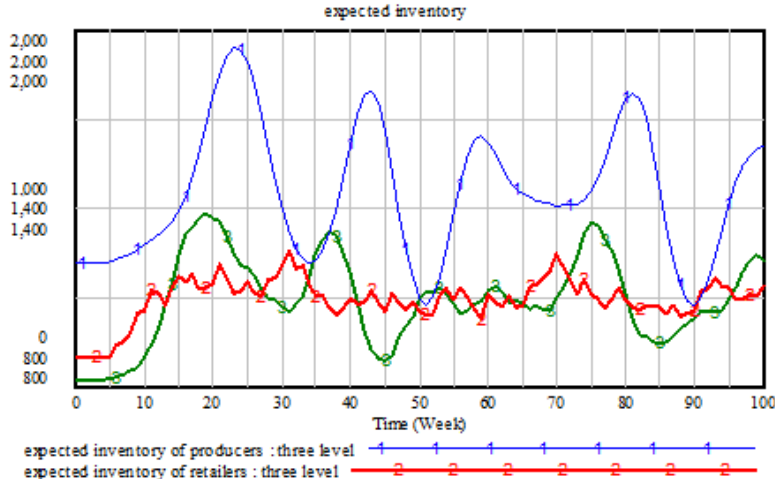

expected inventory of retailers : three level

A. Expected inventory

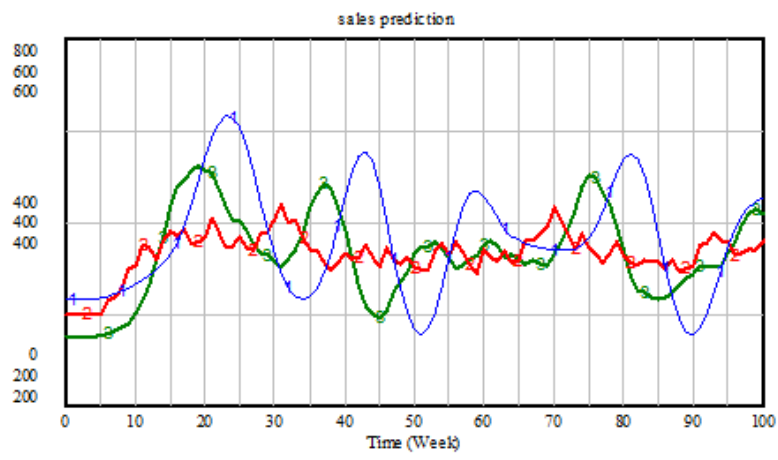

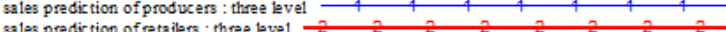
sales prediction of retailers : three level

C. Sales prediction
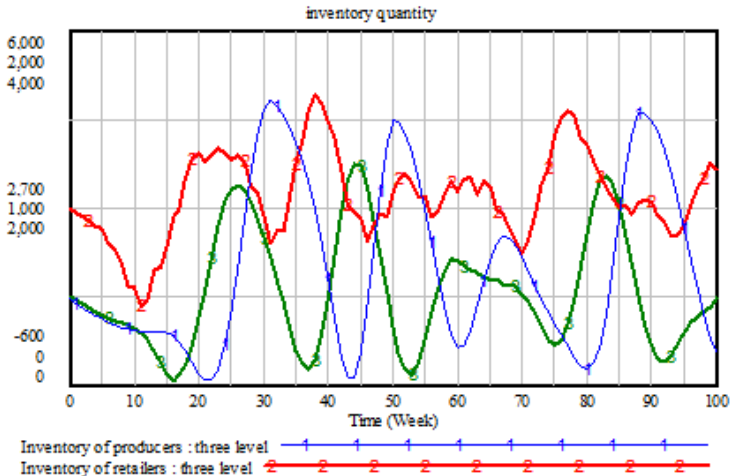
Inventory of wholes alers : three leve

B. Inventory level

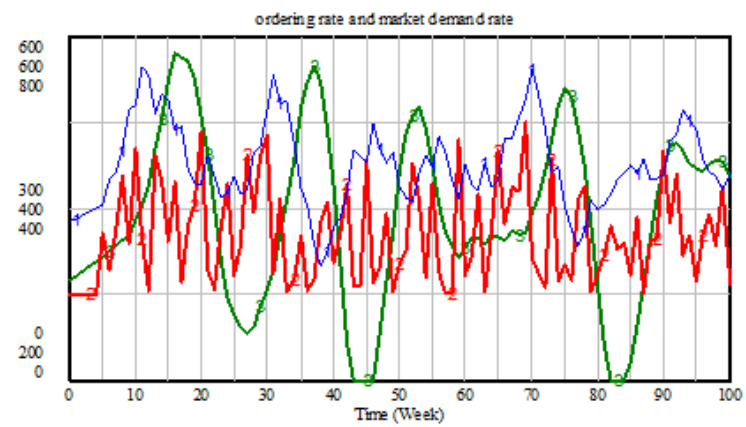

ordering rate of retailers : three level 14 marlet demand rate : three level

D. Ordering rate and market demand rate

Figure 4. Simulating supply chain bullwhip effect.

\subsection{Sales predictions under bullwhip effect}

Figure 4C shows that sales predictions of producers exhibit the largest and longest fluctuations, followed by sales predictions of wholesalers and retailers. The retailers directly interact with the market. Thus, they can use their observations of market demand as information to generate accurate product sales forecasts to guide adjustments they wish to make to the quantity of goods they have on hand, and consequently sales predictions of retailers show the minimum fluctuations. In general, due to the combined influence of uncertain factors and time delays, upstream of supply chain exhibits larger fluctuations than downstream end do. For example, the first valleys in the sales predictions of the retailers, wholesalers and producers appear at 11, 19 and 23 weeks, respectively.

There is a similarity between sales predictions of members and the fluctuations in sales predictions of producers. That is, small fluctuations in retailers' sales predictions cause a larger range of fluctuations in sales predictions of wholesalers and the largest-amplitude fluctuations in sales predictions of producers. The experimental results show that bullwhip effect has a significant effect in three-level supply chain, which has a strong and complex impact on the production planning and inventory control of supply chain.

\subsection{Ordering rates and market demand rate under bullwhip effect}

Figure 4D shows ordering rates and market demand rate under bullwhip effect. The producers show the largest range of fluctuations with variations in market demand rate, followed by producer productivity and ordering rate of wholesalers. The influence of bullwhip effect is most significant in inventory levels, sales predictions and ordering rates and the greatest influence is observed at the upstream end of supply chain. The inventory and order quantities of each member exhibit large fluctuations, and demand information is magnified at each step in supply chain system. 


\section{Discussions}

\subsection{Adjusting the structure of supply chain}

To study the impact of supply chain structure on bullwhip effect, inventory dynamics in two-level supply chain network and four-level supply chain network are studied for comparison with those in three-level supply chain network. The purpose of this investigation is to verify whether bullwhip effect is related to the length of supply chain. In the two-level supply chain, wholesalers are omitted, allowing suppliers to directly trade with retailers. In the four-level supply chain, distributor nodes are additionally considered, resulting in a four-level supply chain model consisting of producers, wholesalers, distributors and retailers.

\subsubsection{Two-level supply chain}

The system models, system boundaries, causal loop diagrams, system flow charts and simulation equations for two-level supply chains are similar to those for the three-level supply chain. And the simulation results for two-level supply chain are shown in Figure 5. Fluctuations in expected inventory levels, inventory levels, sales predictions, ordering rates and market demand rate are all below than three-level supply chain, which implies that as the length of supply chain decreases, bullwhip effect becomes smaller.

\subsubsection{Four-level supply chain}

The simulation results for four-level supply chain are shown in Figure 6.

An analysis of the simulation of four-level supply chain shows that the range of inventory fluctuations is much larger than that for the three-level supply chain.

\subsubsection{Comparison of simulation results}

The simulation results for inventory levels and sales predictions in three kinds of supply chains are shown in Figure 7.

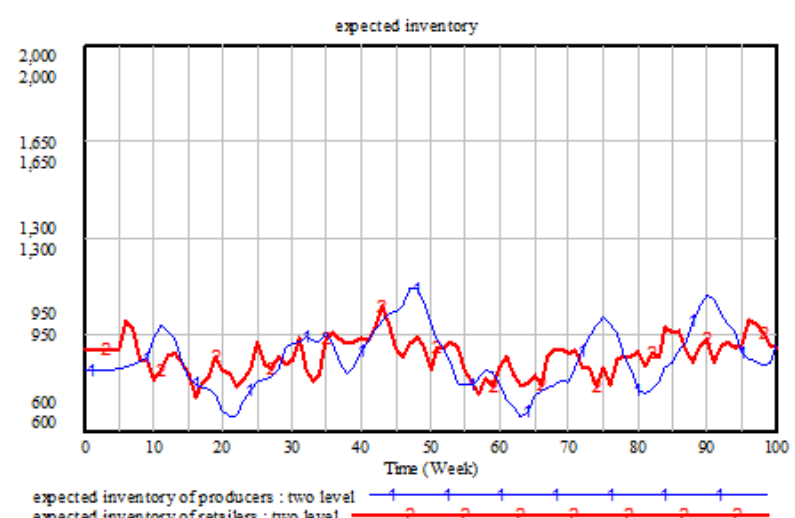

A. Expected inventory

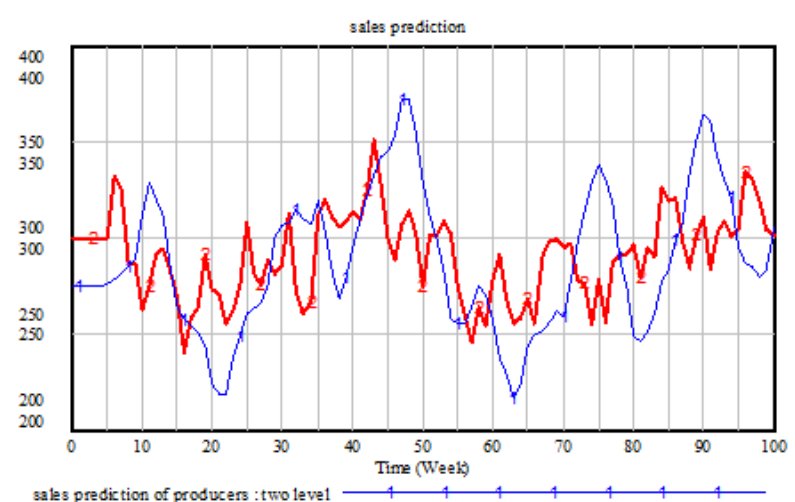

sales prediction of producers : trwo level
sales prediction of fetailers : thro level

C. Sales prediction
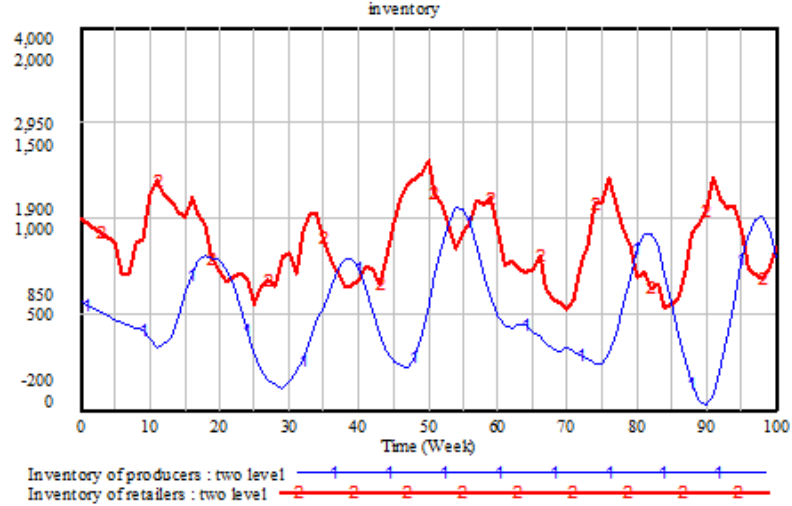

B. Inventory level

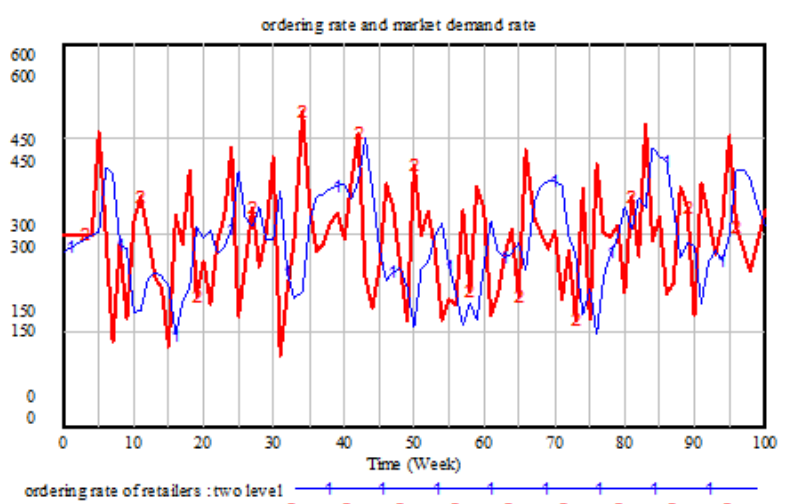

D. Ordering rate and market demand rate

Figure 5. Simulating bullwhip effect in two-level supply chain. 


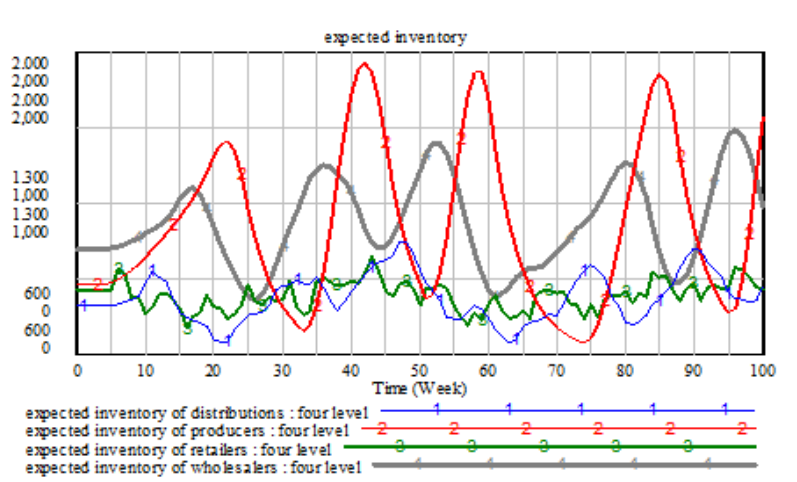

A. Expected inventory

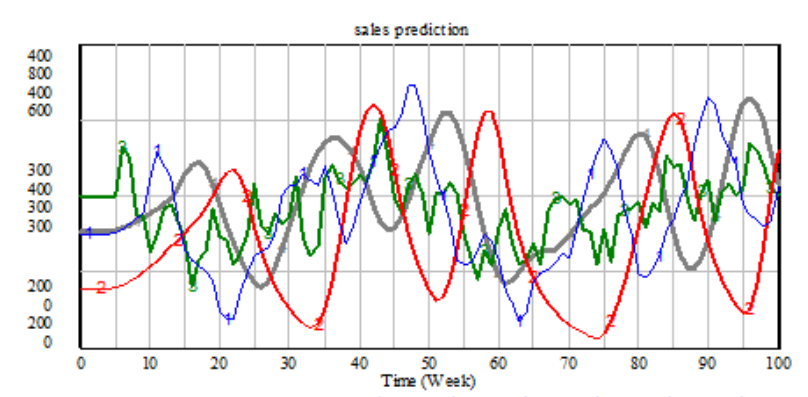

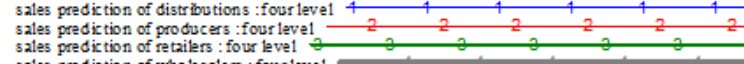

C. Sales prediction
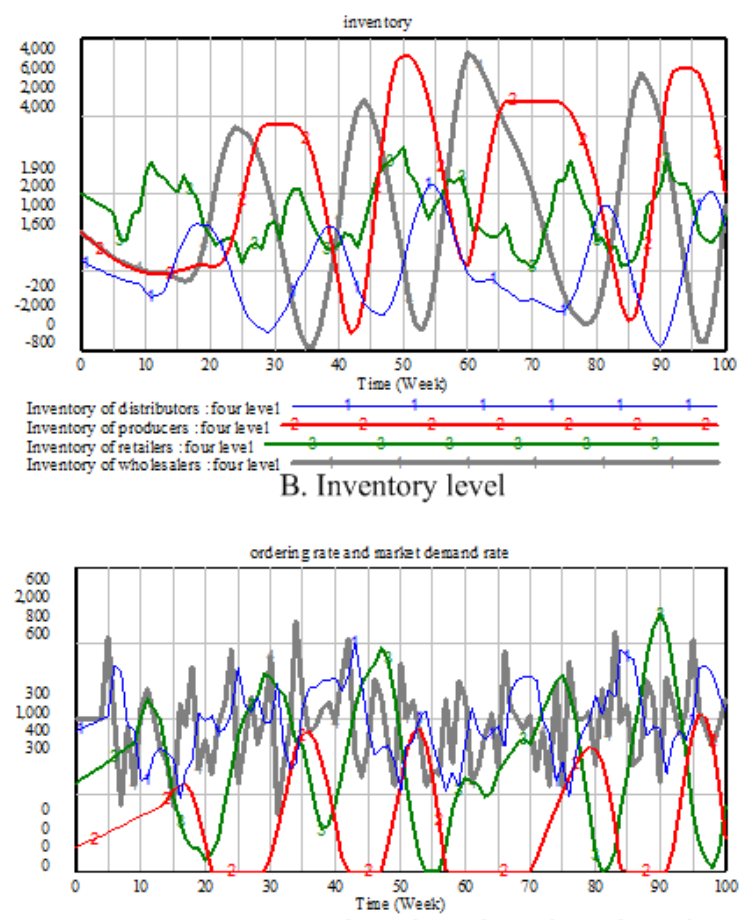

ordering rate of retailes : fous leve1 ordering rate of wholesalers : four lave1 orderng rate of distributions :forts

D. Ordering rate and market demand rate

Figure 6. Simulating bullwhip effect in four-level supply chain.

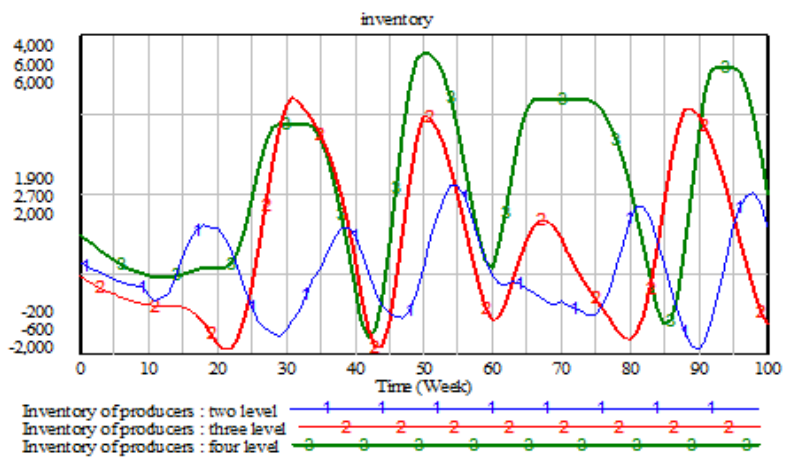

A. Inventory level

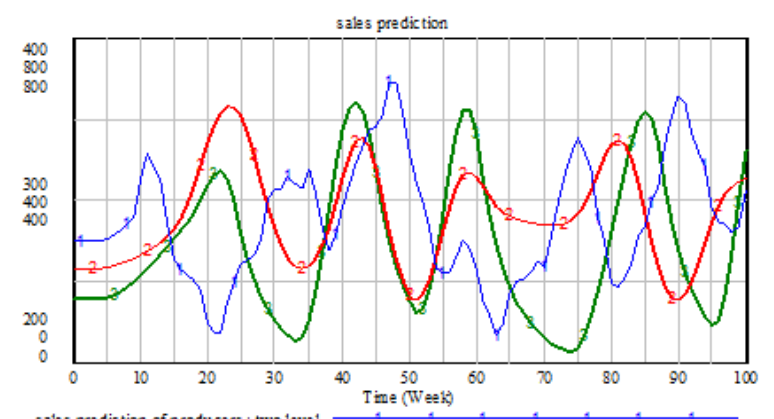

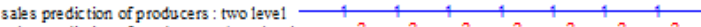
sales prediction of producers: three level

B. Sales prediction

Figure 7. Simulation for two-level, three-level and four-level supply chains.

Simulation results for three kinds of supply chains mentioned above reveals that as the length of supply chain increases, inventory fluctuations of nodes at all levels become increasingly large. In the four-level supply chain, supplier inventory reaches a maximum of 6,000 pieces, which markedly exceeds the maximum amount of inventory in the two-level supply chain.

By comparing inventories and sales predictions of all supply chain members at all levels, it is seen that as the number of nodes in supply chain increases, inventory and production demand of suppliers both increase significantly. Thus, the more participants there are in horizontal level, the more times information is processed and amplified, resulting in a larger distortion of market demand. That is, as the length of supply chain grows, bullwhip effect becomes worse. Therefore, it can be concluded that the organizational structure of supply chain has a great impact on bullwhip effect. Consequently, by either directly or indirectly adjusting the organizational structure of supply chain, bullwhip effect can be weakened 
throughout the entire supply chain.

\subsection{Adjusting the inventory structure of supply chain}

The purpose of this analysis is to investigate the influence of information structure on bullwhip effect in three-level supply chain operating under VMI model. The simulation results for ordering rates of retailers, expected inventories of retailers, inventories of retailers and sales predictions of retailers in VMI supply chain and three-level supply chain are compared in Figure 8.

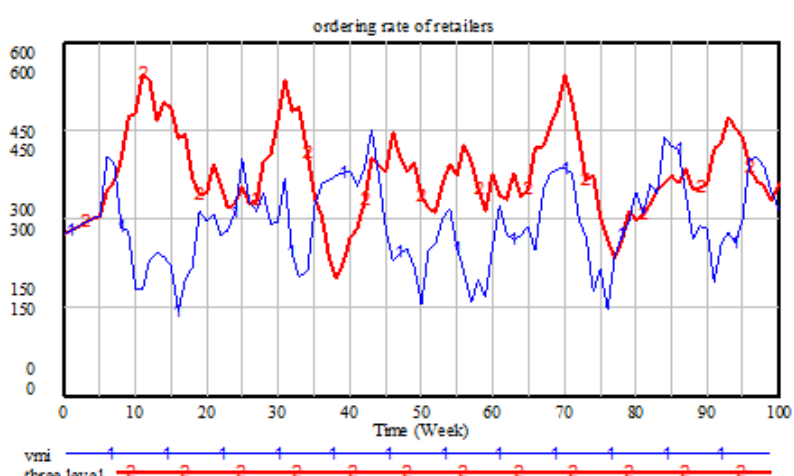

A. ordering rate of retailers

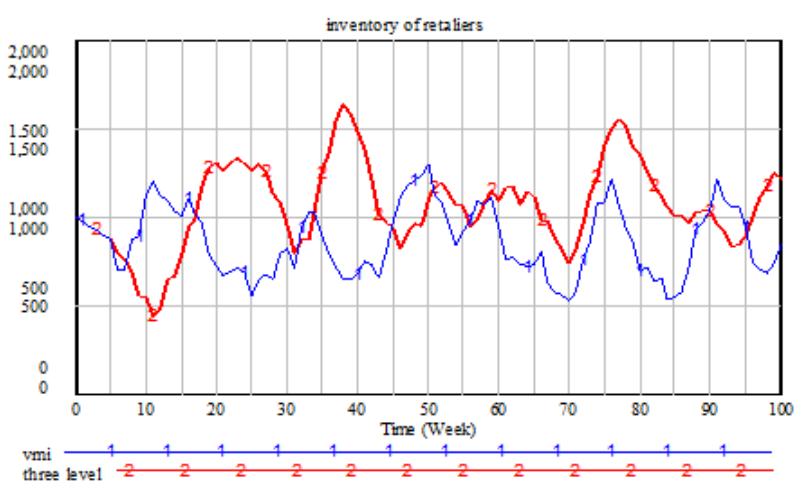

C. Inventory of retailers
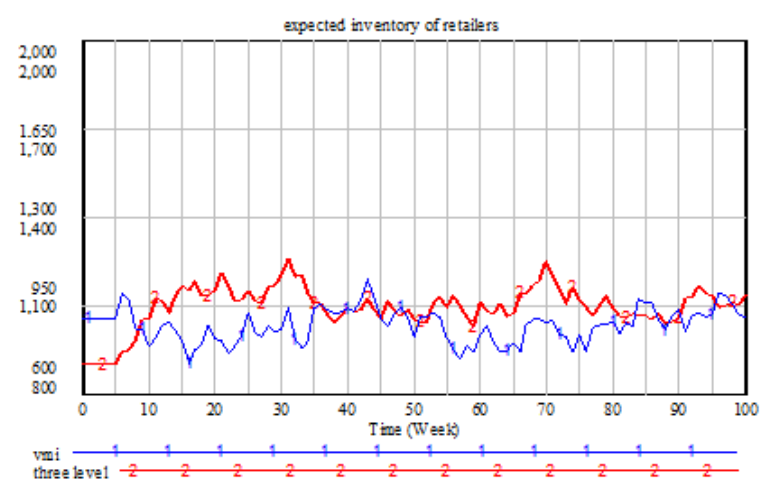

B. Expected inventory of retailers

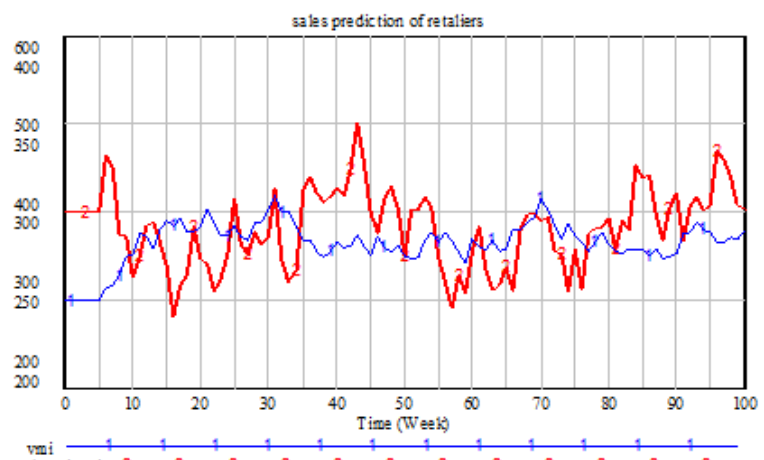

D. Sales prediction $\mathrm{pf}$ retailers

Figure 8. Simulating VMI and three-level supply chain.

\subsection{Tactics for alleviating bullwhip effect}

\subsubsection{Information sharing in supply chain}

The efficiency of information sharing in a supply chain determines the response speed of supply chain. The root cause of bullwhip effect is the inability of supply chain members to effectively account for information on interactions affecting production planning and procurement decisions. Therefore, information sharing among all nodes is one of the most direct ways to alleviate bullwhip effect. If the relevant information such as customer order quantity, existing inventory quantity, sales volume data of each enterprise can be circulated among various enterprises in supply chain efficiency, enterprises at all levels of supply chain can understand the demand of their downstream enterprises as soon as possible. The demand changes will be responded in a short period of time and bullwhip effect will be well controlled. In addition, information sharing can also promote mutual trust among members of supply chain, which can facilitate agile response to rapidly changing market demands.

First, information asymmetry should be weakened and information sharing among supply chain nodes should be increased. Second, establishment of information exchange platform for supply chain nodes is an important way to improve information sharing and alleviate bullwhip effect. Relevant information technology such as Internet and electronic data interchange (EDI) should be used to establish real-time sharing information platforms. Only when information is shared in a wider scope can the actual downstream demand in supply chain be accurately captured, thereby reducing information asymmetry and alleviating bullwhip effect. 


\subsubsection{Adjusting supply chain structure}

Through the simulation of supply chain structure, it can be seen that the more nodes are present in supply chain system, the more obvious bullwhip effect. Therefore, reducing the number and accelerating information flow can also ensure the accuracy of order information and significantly reduce bullwhip effect. With the horizontal and vertical scale of supply chain increasing, the number of supply chain members will be increased and the real demand information is processed and distorted more frequently. Therefore, the horizontal and vertical scales in supply chain should be reduced as much as possible to weak the impact of supply chain information distortion. At the same time, new business models such as direct sales can be adopted to reduce the horizontal level of supply chain so as to contact the final customer and grasp the market demand as much as possible.

\subsubsection{Other Tactics}

Retailers can anticipate consumer demand using multiple forecasting methods, thereby ensuring that they will order a reasonable number of products from upstream side of supply chain and achieve the maximum economic benefit with the minimum inventory cost. Wholesalers can place orders with producers as far ahead as possible without affecting normal business operations. Manufacturers can find alternative products to slow down bullwhip effect on products. In addition, producers can survey and supplement inventory levels of wholesalers and retailers ahead of time to avoid superimposition of inventory fluctuations of downstream enterprises and thus effectively suppress bullwhip effect.

According to the actual characteristics of supply chain structure, advanced inventory management technology such as VMI should be used to achieve the coordination of overall supply chain. The main idea of VMI is to integrate suppliers with their downstream enterprises. Suppliers set up inventory under mutually agreements and obtain the required inventory level of downstream enterprises at any time so suppliers can respond to market changes and consumer demand more efficiently. VMI can not only effectively reduce the total number of warehouses in the entire supply chain to reduce the uncertainty of supply chain, but also transport goods accurately and timely, thereby weakening bullwhip effect.

\section{Conclusions}

Based on supply chain theory, a three-level supply chain composed of suppliers, wholesalers and retailers was considered in this paper. Using this supply chain model, causal loop diagram for three-level supply chain system was established by means of a system dynamics model. Then, the flow chart and simulation equations for three-level supply chain system were simulated using Vensim 5.6 software. It is found that both supply chain level and inventory management method have a direct impact on bullwhip effect. On this basis, practical measures to alleviate bullwhip effect are proposed from the perspective of information sharing, optimizing supply chain structure and information technology application.

However, there are many aspects of bullwhip effect needed to be studied. For example, although this paper proposes the delay measures of bullwhip effect, it is difficult to achieve the mutual influence of various measures. Therefore, the delay strategy evaluation of bullwhip effect will be a further study in the future.

\section{Acknowledgements}

This paper is supported by Shandong Social Science Foundation (Grant No. 19BJCJ20); Shandong Natural Science Foundation (Grant No. ZR2020MG069).

\section{References}

[1] Li, H. B., Pedrielli, G., Lee, L. H., Chew, E. P. (2017). Enhancement of Supply Chain Resilience Through Inter-Echelon Information Sharing. Flexible Services and Manufacturing Journal, 29, 260-285.

[2] Parra, J. F., Jaramillo, P., Aramburo, S. A. (2018). Metaheuristic Optimization Methods for Calibration of System Dynamics Models. Journal of Simulation, 12, 190-209.

[3] Chen, L., Lee, H. L. (2012). Bullwhip Effect Measurement and Its Implications. Operations Research, 60, 771-784.

[4] Choi, T., Li, J., Wei, Y. (2013). Will A Supplier Benefit From Sharing Good Information With A Retailer? Decision Support Systems, 56, 131-139.

[5] Cui, R., Allon, G., Bassamboo, A., Mieghem, J. V. (2015). Information Sharing in Supply Chains: An Empirical and Theoretical Valuation. Management Science, 61, 2803-2824.

[6] Khosroshahi, H., Husseini, S. M. M., Marjani, M. R. (2016). The Bullwhip Effect in A 3-Stage Supply Chain Considering Multiple Retailers Using A Moving Average Method For Demand Forecasting. Applied Mathematical Modelling, 40, 8934-8951. 
[7] Costantino, F., Gravio, G. D., Shaban, A., et al. (2015). SPC Forecasting System to Mitigate the Bullwhip Effect and Inventory Variance in Supply Chains. Expert Systems with Applications, 42, 1773-1787.

[8] Hassanzadeh, A., Jafarian, A., Amiri, M. (2014). Modeling and Analysis of the Causes of Bullwhip Effect in Centralized and Decentralized Supply Chain Using Response Surface Method. Applied Mathematical Modelling, 38, 2353-2365.

[9] Nepal, B., Murat, A., Chinnam, R. B. (2012). The Bullwhip Effect In Capacitated Supply Chains With Consideration for Product Life-Cycle Aspects. International Journal of Production Economics, 136, 318-331.

[10] Isaksson, O. D., Seifert, R. W. (2016). Quantifying The Bullwhip Effect Using Two-Echelon Data: A Cross-Industry Empirical Investigation. International Journal of Production Economics, 171, 311-320.

[11] Naim, M. M., Spiegler, V. L., Wikner, J., Vikner, J., Towill, D. R. (2017). Identifying the Causes of the Bullwhip Effect by Exploiting Control Block Diagram Manipulation with Analogical Reasoning. European Journal of Operational Research, 263, 240-246.

[12] Linnéusson, G., Ng, A. C., Aslam, T. (2018). Quantitative Analysis of A Conceptual System Dynamics Maintenance Performance Model Using Multi-Objective Optimisation. Journal of Simulation, 12, 171-189.

[13] Agrawal, S., Sengupta, R. N., Shanker, K. (2009). Impact of Information Sharing and Lead Time on Bullwhip Effect and On-hand Inventory. European Journal of Operational Research, 192, 576-593.

[14] Dragovic, B., Tzannatos, E., Park, N. K. (2017). Simulation Modelling in Ports and Container Terminals: Literature Overview and Analysis by Research Field, Application Area and Tool. Flexible Services and Manufacturing Journal, 29, 4-34.

[15] Warren, L. T., Chang, P. C. (2010). Impacts of Forecast, Inventory Policy, and Lead Time on Supply Chain Inventory: A Numerical Study. International Journal of Production Economics, 128, 527-537.

[16] Hussain, M., Saber, H. (2012). Exploring The Bullwhip Effect Using Simulation And Taguchi Experimental Design. International Journal of Logistics: Research and Applications, 15, 1-19.

[17] Heshmat, M., Eltawil, A. (2018). A System Dynamics-Based Decision Support Model For Chemotherapy Planning. Journal of Simulation, 12, 283-294.

[18] Shamsaei, F., Vyve, M. V. (2017). Solving Integrated Production and Condition-Based Maintenance Planning Problems by MIP Modelling. Flexible Services and Manufacturing Journal, 29, 184-202. 